\title{
Evaluación escolar de la escritura inicial *
}

\section{Rosa M. ${ }^{a}$ Bellés **}

Instituto Municipal de Educación de Barcelona

\section{INTRODUCCION}

Evaluar es un acto social generalizado en muchas y variadas situaciones. Algunas de las definiciones de evaluación así lo muestran: "el acto por el cual, en relación a un acontecimiento, un individuo o un objeto, se emite un juicio refiriéndose a uno o muchos criterios" (Noizet y Caverni, 1978). Sin embargo, a pesar de que valorar sea usual, a menudo la evaluación es polémica dentro del contexto escolar. Polémica, por dos razones: por un lado, en tanto que siendo un elemento clave dentro del sistema educativo tiene consecuencias que lo sobrepasan. En efecto, «la evaluación comporta un elemento esencialmente comparativo y es allí donde radica el problema, en la actualización de las diferencias entre los alumnos y en cómo la norma derivada de la evaluación pasa a ser el predictor de los éxitos o fracasos posteriores" (Perrenoud, 1979). Y por otro lado, la evaluación es polémica por su complejidad. En la práctica escolar esta complejidad afecta fundamentalmente dos tipos de decisiones. Una se refiere a la representatividad de la evaluación, es decir, a decisiones en torno a qué datos observables son medibles o al menos dignos de ser medidos (De Ketele, en Bonboir, 1975), cómo justificar que la capacidad reconocida por el maestro dentro del aula se seleccione como la competencia real del alumno, o cuál es el momento oportuno para que la ejecución evaluada sea relevante de la adquisición de un aprendizaje. Otro tipo de decisiones insisten sobre cuáles son los instrumentos de medición que generan menos margen de error. Algunas de las soluciones adoptadas para afrontar este problema han sido la asimilación formal de la evaluación a los tests psicológicos-considerados como ejemplos de uobjetividad»- o la aplicación de tratamientos estadísticos a los datos resultantes de la evaluación.

En la última década el énfasis se ha puesto en la crítica a la evaluación sumativa y en el intento de suplantarla por la evaluación formativa. La presuposición que ha imputado el cambio es de que esta última, continua por definición, neutraliza muchos de los problemas vinculados a la evaluación. La evaluación formativa se interesa tanto por el proceso de enseñanza-aprendizaje como por la adecuación del programa pedagógico. De la evaluación formativa se ha dicho que tiene como intención la homogeneización. Ello contrasta con la evaluación sumativa, a la que con frecuencia se le atribuye una estrecha relación con el fracaso escolar de 
los alumnos. Pero sea cual sea el tipo de evaluación adoptado en las escuelas o en las aulas, un problema persiste: ¿qué se observa en las producciones de los alumnos y qué relevancia tiene lo observado en el momento de evaluar?

El presente trabajo trata sobre la evaluación de la adquisición inicial de la lengua escrita. Sabemos que un alto porcentaje de lo que se califica "fracaso escolar» tiene en común el deficiente uso de la lengua escrita. El primer «signo de alarma» de los llamados «fracasados escolares) normalmente aparece en el inicio del aprendizaje escolar. Se puede afirmar en consecuencia que la mayor parte de los fracasos escolares deben imputarse a la adquisición inicial de la lecto-escritura. Teniendo presente estas consideraciones, interesa confrontar los aspectos que para un enseñante son relevantes al evaluar y los aspectos que al estudiar la evolución conceptual de la escritura fueron necesarios destacar.

Estudios anteriores han puesto de manifiesto que existe una "historia preescolar de la escritura»; antes de que los niños logren escrituras alfabéticas se formulan y comprueban hipótesis respecto al sistema escrito. El proceso de apropiación de la escritura por parte del niño supone dar respuesta a dos cuestiones capitales: qué es lo que la escritura representa y cuál es el modo convencional de representación. Al estudiar la escritura infantil se han establecido cambios cualitativos en la adquisición de este dominio específico en función de las respuestas que los niños dan al intentar contestar las cuestiones anteriores.

La investigación pionera, desde un encuadre psicogenético, de la adquisición de la lengua escrita por parte del niño, reveló distintos momentos en la evolución de dicha adquisición (Ferreiro y Teberosky, 1979). Investigaciones posteriores (Ferreiro y Gómez Palacio, 1981), describieron con mayor profundidad las caracteristicas de las escrituras espontáneas infantiles. En el presente trabajo los modos de construcción de escrituras espontáneas usados para seleccionar las copias que los sujetos deben evaluar, se describen de la siguiente manera:

- Inicialmente, no existen modos de diferenciar gráficamente las escrituras. El niño está centrado en la propia actividad motriz con independencia de los resultados gráficos que obtenga.

- Las escrituras posteriores son diferenciadas. Se caracterizan por el dominio de un repertorio limitado de formas más o menos cercanas a las convencionales ( $y$ a menudo provistas por el modelo del nombre propio), por la posibilidad de controlar la cantidad de grafías de la escritura y la de establecer relaciones posicionales entre ellas. Así, el repertorio, la cantidad y la posición de las grafías proveen modos de diferenciación entre las distintas producciones escritas.

- Luego, el trabajo de poner en relación dos sistemas: el gráfico y el lenguaje. Esta relación toma la forma de una correspondencia entre unidades del lenguaje (sílabas o fonemas según el modo de analizar los componentes de la emisión sonora) y unidades gráficas. La primera relación se establece entre sílabas y grafías: de una emisión, se analizan tantas grafías como silabas. Las escrituras que responden a este tipo de correspondencia fueron denominadas «escrituras silábicas» (Ferreiro y Teberosky, 1979). Luego es posible establecer una correspondencia entre fonemas y grafias, estas escrituras se organizan según las reglas de las «escrituras alfabéticas». Entre unas y otras se han ubicado las «escrituras silábico-alfabéticas" intermediarias entre la representación de la sílaba y del fonema.

Está claro que en estos casos se establece una correspondencia sonora, sea silábica o fonética. Pero ello no garantiza la estabilidad de relación entre determinadas unidades gráficas y determinadas unidades sonoras. Esta estabilidad se logra por la aprehensión de los valores sonoros convencionales del sistema de escritura alfabético. Por ello hablamos de escritura con correspondencia sonora que pueden tener o no valor sonoro convencional. Evidentemente, las escrituras más avanzadas, en el sentido de más próximas a los modelos adultos convencionales, tienen valor sonoro convencional al menos para la mayoria de las unidades gráficas. 

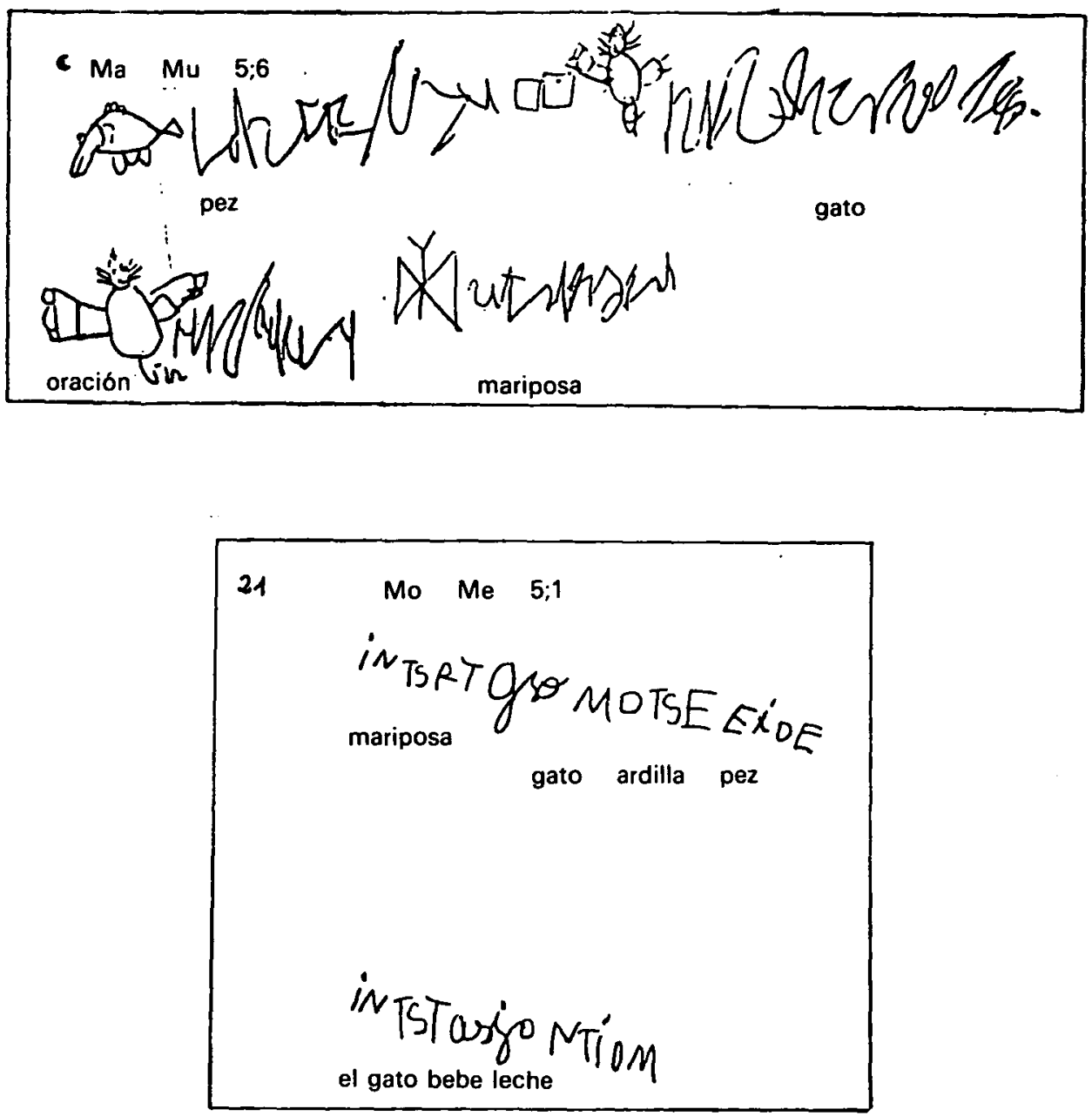

H Jo Ri $5 ; 2$
$|\wedge t \cdot \Delta 3|$
LOAT laOLI poim
girafa
esquirol
gat
tigre
papallona

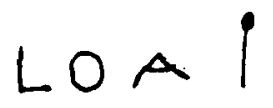
el gat beu liet 
Así, los diferentes niveles conceptuales por los que pasan los niños en su comprensión del sistema escrito son los siguientes ${ }^{1}$ :

- Escrituras indiferenciadas.

- Escrituras diferenciadas en función del repertorio, la posición y la cantidad.

- Escrituras con valor sonoro convencional sin correspondencia sonora.

- Escrituras con correspondencia sonora silábica (con o sin valor sonoro convencional).

- Escrituras con correspondencia sonora silábico-alfabética (con o sin valor sonoro convencional).

- Escrituras con correspondencia sonora alfabética (con o sin valor sonoro convencional) ${ }^{2}$.

En el caso concreto del aprendizaje de la lengua escrita, se pretende saber, dadas una serie de producciones infantiles, qué aspectos de las mismas pondera el maestro al evaluar $y$, por consiguiente, cuáles son sus criterios al encarar dicha tarea. Interesa contrastar estos criterios con los resultados del diagnóstico psicogenético de la evolución conceptual de la escritura. $\mathrm{El}$ análisis de las concordancias o discrepancias entre ambos puede abrir vías para entender mejor algunos aspectos del fracaso inicial en el aprendizaje de la lengua escrita.

\section{SITUACION EXPERIMENTAL}

a) El trabajo que se presenta trata de hallar cuáles son los fenómenos que se producen con cierta regularidad en el transcurso del acto de evaluar que afectan a los juicios emitidos. Para ello se han realizado entrevistas individuales en catalán a profesores en ejercicio en ciclo inicial de Educación General Básica, durante el segundo trimestre del curso escolar. Las entrevistas fueron registradas y transcritas manualmente. Se analizan diez de estas entrevistas.

b) Para que los profesores hicieran la evaluación fueron seleccionadas copias reales de escrituras infantiles. Estas producciones de escritura espontánea, de cuatro palabras y una oración, fueron obte- nidas en situación individual de diagnóstico según la línea elaborada por Ferreiro y Teberosky (1979). Dichas producciones correspondían a alumnos del último curso de preescolar (cinco-seis años). Tres de ellos eran repetidores $y$, por tanto, con un año más. Pertenecian a tres escuelas públicas de la ciudad de Barcelona. Ninguno de los maestros entrevistados trabajaba en las escuelas donde se recogieron las producciones de los niños. Las entrevistas de diagnóstico con los niños fueron efectuadas durante el primer trimestre del mismo curso escolar. Las producciones, así como la entrevista diagnóstica, se realizaron en lengua catalana o castellana, según la lengua de origen de cada alumno.

c) El entrevistador ofreció datos constantes a los sujetos evaluadores. Los datos eran de tres tipos:

- Copias de escritura.

- Información sobre condiciones generales de las muestras de escritura (explicación de la situación de diagnóstico con los niños, pertenencia a distintas escuelas y niños, grado escolar de los alumnos que las realizaron, etc.).

- Información sobre condiciones particulares de cada una de las muestras de escritura (edad del alumno en años y meses, iniciales de su nombre y apellido, direccionalidad de la escritura y lengua de origen en los casos en que la producción no fuera suficientemente legible). Este tipo de informaciones fue incluido en cada una de las producciones.

Con las informaciones sobre condiciones generales y particulares, el sujeto entrevistado obtenía datos a priori sobre las producciones que debía evaluar.

d) Las muestras de escrituras de niños que debían evaluar los sujetos fueron presentadas en tres series. Todas las producciones de una misma serie se dieron simultáneamente. Después de evaluar una serie de escrituras se presentaba la siguiente. De este modo la situación experimental constaba de tres fases:

Primera fase, serie 1.-Esta serie estaba compuesta por trece producciones correspondientes a distintos momentos de la 


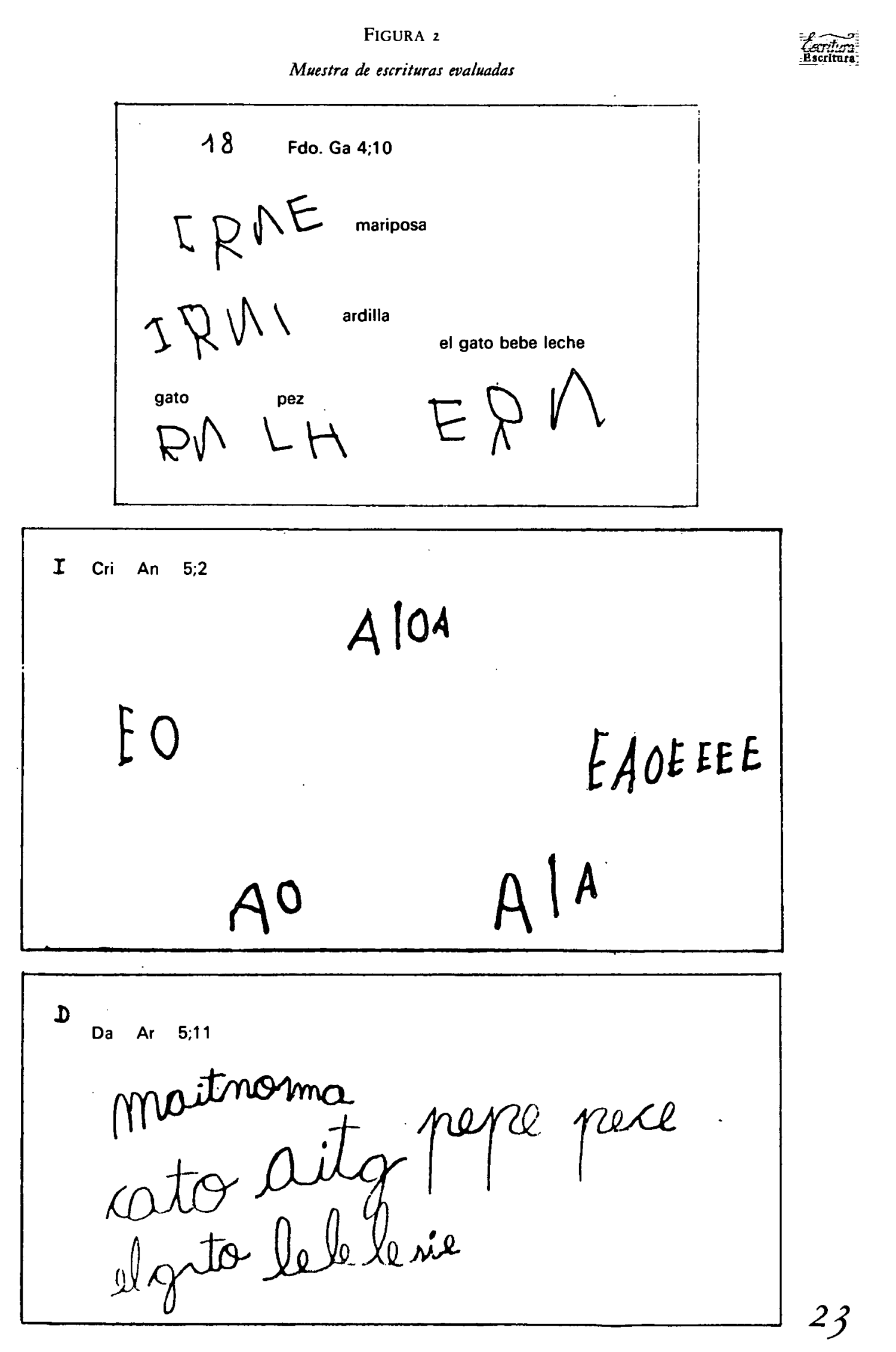


evolución conceptual de la escritura. Las producciones ejemplificaban los patrones evolutivos siguientes: escrituras no diferenciadas gráficamente, diferenciadas gráficamente por repertorio, posición y cantidad, diferenciadas gráficamente con valor sonoro convencional y escrituras con correspondencia sonora en los tres niveles posibles: silábicas (con y sin valor sonoro convencional), silábico-alfabéticas y alfabéticas con valor sonoro convencional. En la serie había dos copias de cada uno de estos patrones. A cada producción se le asignó arbitrariamente una letra de imprenta mayúscula.

Se solicitó a los entrevistados una calificación de las escrituras en términos cuantitativos desde $\circ$ a s puntos y la justificación de la nota que habian otorgado.

Segunda fase, serie 2.- Se presentó una serie de ocho producciones en las que había dos copias de cada uno de los cuatro patrones evolutivos iniciales enumerados para la serie I. A las copias incluidas en esta segunda serie se les asignó arbitrariamente letras cursivas.

Se solicitó al entrevistado el mismo tipo de evaluación y justificación.

Tercera fase, serie 3.- -Se pidió una nueva evaluación sobre pares equivalentes a las escrituras de la serie I. La composición era pues de trece copias a las que se asignó un número para reconocerlas.

La tarea solicitada era igual que para las series anteriores pero, en este caso, el experimentador anunciaba que podía dar información adicional sobre las producciones, si le era solicitada. En el cuadro I se presenta la clasificación evolutiva de las muestras de escritura.
Los objetivos de la utilización de las tres series fueron los siguientes:

- Confrontar las series paralelas i y 3 con el fin de constatar la conservación o modificación de criterios de evaluación de las escrituras. La hipótesis de partida era que podía haber modificación de criterios, tanto a raíz de la información adicional que podia ser dada en la serie 3, como por otras causas generadas durante el transcurso temporal del acto de evaluar.

- Confrontar la serie 2 con las I y 3 . La finalidad era analizar si las escrituras de la serie 2 podian ser mejor discriminadas que las paralelas en las otras series. De confirmarse esta hipótesis, el modo de presentación de las escrituras - de forma aislada (serie 2) o dentro de una serie de niveles más heterogéneos (series I y 3) - influiría en la selección de índices considerados por los sujetos en el momento de evaluar. Ello daría como resultado un desplazamiento de la escala de evaluación.

- Revelar cuál fue el modo de evaluación seguido por los sujetos. Investigaciones precedentes sobre evaluación (Noizet y Caverni, 1978), han puesto de manifiesto que existe una discordancia entre lo que los evaluadores dicen evaluar y lo que hacen realmente en el momento de evaluar. En esta situación la propuesta era únicamente de realizar una evaluación de escrituras espontáneas. Pero esta evaluación exigía a los evaluadores dos tipos de tareas: la calificación y la justificación del puntaje otorgado. De este mo-

Cuadro I

\begin{tabular}{|c|c|c|c|}
\hline \multirow{2}{*}{$\begin{array}{l}\text { Niveles de construcción } \\
\text { de escrituras espontáneas }\end{array}$} & \multicolumn{3}{|c|}{ Escrituras que componen las series } \\
\hline & Serie $\mathbf{I}$ & Serie 2 & Serie 3 \\
\hline No diferenciadas & C, $\mathrm{Q}$ & $f, n$ & I 3,17 \\
\hline Diferenciadas por cantidad, repertorio y posición & $\mathrm{K}, \mathrm{O}$ & $\mathrm{a}, \mathrm{h}$ & 15,21 \\
\hline Diferenciadas con valor sonoro convencional ... & $\mathrm{H}^{*}$ & $\mathrm{~d}, \mathrm{i}$ & $9^{*}$ \\
\hline Silábicas & & & \\
\hline Sin valor sonoro convencional & $\mathrm{N}, \mathrm{S}$ & $\mathrm{j}, \mathrm{m}$ & 10,18 \\
\hline Con valor sonoro convencional $\ldots \ldots \ldots \ldots \ldots$ & $\mathrm{G}, \mathrm{I}$ & & 4,12 \\
\hline Silábico-alfabéticas con valor sonoro convencional . . & $\mathrm{D}, \mathrm{P}$ & & 1,20 \\
\hline Alfabética con valor sonoro convencional $\ldots \ldots \ldots$ & L, R & & 3,14 \\
\hline
\end{tabular}

* Escrituras diferenciadas con valor sonoro convencional sólo se ha incluido un ejemplar en las series 1 y 3, debido a los pocos niños encontrados en este nivel de escritura. 
do, la recogida de datos, tanto del valor atribuido como del proceso de atribución, podía permitir el análisis más fidedigno de la interrelación entre los aspectos cualitativos (criterios usados, estabilidad, dependencia, etc.), y los cuantitativos (calificaciones) intervinientes en esta situación de evaluación.

- Confrontar, por último, los aspectos relevantes desde la práctica pedagógica con los datos provistos por la teoría psicogenética de la evolución en la construcción de escrituras por parte del niño.

\section{Puntajes atribuidos}

Se ha optado por utilizar la multicorrección o método del jurado (A. Bonboir, 1974) como técnica de moderación de las divergencias de evaluación dadas las características de la situación experimental —entrevistas individuales.

\section{I.a) Puntajes otorgados para la serie I}

Las puntuaciones otorgadas a las escrituras de esta primera serie van desde o a 5 puntos. Los valores medios de las producciones alcanzan un mínimo de 0,66 puntos y un máximo de 4,88 puntos.

Si se considera una misma producción la dispersión de las puntuaciones - diferencia entre la nota mínima y máxima dada por los evaluadores - alcanza una oscilación entre un mínimo de o,s puntos y un máximo de 3 puntos. Por otra parte, si se consideran las dos producciones diferentes, pero de un mismo nivel conceptual, se observa la misma dispersión o, 5 y 3. La mayor homogeneidad entre los puntajes en ambos casos corresponden a las escrituras de tipo alfabético. Mientras que la heterogeneidad se da al evaluar las escrituras de tipo silábico-alfabético.

La media resultante para la serie 1 es de $\bar{X}=1,92$ puntos. Por encima de dicho valor se sitúan las copias de escrituras alfabéticas y silábico-alfabéticas. Estos valores medios si bien tienen globalmente un puntaje progresivo, su progresión no es paralela a la evolución psicogenética. En efecto, escrituras que establezcan la correspondencia sonora con el lenguaje como las que no, o que atribuyan valor sonoro convencional o no lo atribuyan, obtienen medias cercanas a un punto o a dos puntos, pero sin un aumento gradual de acuerdo al progreso evolutivo. Considerando que normalmente en la escolaridad ordinaria suele tomarse la nota media obtenida por los alumnos de un mismo curso como punto a partir del cual se establecen los distintos rangos de rendimiento en los aprendizajes, se podrían inferir los siguientes aspectos:

- Sólo los alumnos con producciones silábico-alfabéticas y alfabéticas superarian satisfactoriamente la evaluación de escritura al dictado. No obstante, si en lugar de la nota media de la serie, se toma la nota media de la escala (2,5 puntos) se observa que una de las producciones silábico-alfabéticas también sería suspendida por no alcanzar más que 2,4I puntos.

- Las producciones aprobadas representan el 30,7 por roo sobre el total de la serie. Si de esta evaluación dependiera realmente la asignación de calificaciones en términos de aprobado/suspenso, el 69,3 por 100 de alumnos estarían suspendidos.

- Las edades de los alumnos, cuyas producciones son incluidas en la serie, son de S, I a S,I I años. El nivel de rendimiento exigido por los distintos evaluadores para que las producciones sean aprobadas es de escrituras silábico-alfabéticas y alfabéticas para dichas edades.

\section{I.b) Puntajes otorgados para la serie 2}

También en esta serie los evaluadores han asignado puntajes desde cero a cinco puntos. La dispersión de puntaje para una misma producción llega a ser de dos puntos como mínimo y de cinco como máximo. Ello es debido a que los evaluadores o bien han mantenido la relación entre puntuaciones y características de la producción usadas en la serie $\mathrm{I}$, o bien han usado todas las posibilidades de la escala de puntuación, prescindiendo de las distintas características de las copias. En el primer caso la valoración de las escrituras de igual nivel conceptual tienen notas equiparables en ambas series ( 1 y 2) $y$ en el segundo caso, escrituras de igual 
calidad se sobrestiman si están ubicadas en la serie 2. Es en esta serie donde lo que se denomina «ecuación personal del evaluador" (A. Bonboir, I974) - grado de severidad o indulgencia en la puntuación de las copias - se muestra más evidente.

Los valores medios de las producciones van desde un minimo de 0 , 50 puntos a 1,75 de máximo. Tampoco en esta serie las medias aumentan progresivamente en relación a la calidad evolutiva de las producciones. Pero las escrituras menos evolucionadas de la serie y las más evolucionadas son las que reciben puntajes menos y más altos respectivamente.

Dado el alejamiento entre la media de la serie $-\overline{\mathrm{X}}=1,20-$ y la de la escala ofrecida $-\overline{\mathrm{X}}=2,5-$ es de suponer que, trasladadas hipotéticamente a una situación escolar real; todas estas escrituras serían consideradas suspendidas.

\section{I.c) Puntajes otorgados para la serie 3}

En esta tercera serie también se registran puntuaciones de cero a cinco. La dispersión de las puntuaciones de los distintos evaluadores, para los pares de producciones de los niveles, es mayor. La dispersión minima es de un punto y la máxima es de 4,5 puntos. También es más frecuente, un evaluador califica con cero puntos todas las escrituras excepto las alfabéticas. La mayor homogeneidad entre los jueces corresponde a los puntajes de una de las escrituras alfabéticas que sólo obtiene un punto de dispersión. Por el contrario, una escritura silábico-alfabética obtiene 4,5 puntos de dispersión entre las puntuaciones adjudicadas.

Los valores medios de los puntajes de las producciones oscilan entre 0,75 puntos (muestras de escrituras no diferenciadas) y 4,66 (alfabéticas). Las escrituras comprendidas en niveles intermedios, nuevamente, ofrecen valores medios oscilantes.

En esta serie también ocurre que, si se trasladan hipotéticamente al aula los resultados, se observa que la media de la serie es de dos puntos. La sobrepasan sólo las escrituras alfabéticas, silábico-alfabéticas y una de las muestras silábicas. Por el contrario, si se utilizara la media de la escala $(\overline{\mathrm{X}}=2,5)$ la superarían sólo las escrituras alfabéticas y una de las silábico-alfabéticas.

Según se optara por la media de la serie o de la escala, el 38,46 por 100 o el 23,07 por 100 de los alumnos obtendrían respectivamente notas por encima de la media, en tanto que el 61,54 y 76,93 por roo suspenderian.

Consecuentemente podria deducirse que el conocimiento mínimo del sistema escrito requerido para aprobar es de tipo silábico con valor sonoro convencional si se considera la media de la serie o silábico-alfabético con valor sonoro convencional si se considera la media de la escala.

No obstante, la adquisición de estos niveles de escritura no garantizaría el aprobado a todos los alumnos con producciones de estas caracteristicas. Las distintas puntuaciones obtenidas para los pares de escrituras de estos niveles así lo prueban.

\section{I.d) Confrontación de los puntajes entre series}

Al analizar los puntajes de las tres series resalta:

- Las puntuaciones van desde cero a cinco puntos, pero todos los entrevistados fraccionan los valores enteros. Los evaluadores han aceptado la escala de notación impuesta, pero adaptándola: o bien han aumentado la cantidad de gradaciones, o bien han utilizado sólo una parte del margen de variación posible - caso de la serie 2-. Estos dos tipos de estrategias indican que la finalidad es la de establecer una relación muy precisa entre las puntuaciones y los discriminadores que a juicio de los evaluadores operan en las muestras de escritura.

- Las notas dadas para una misma producción o para las distintas producciones de un mismo nivel conceptual son dispersas. La mayor homogeneidad entre los evaluadores se da en la valoración de las escrituras extremas. (escrituras no diferenciadas y escrituras alfabéticas). Esto indica que es en estos niveles donde los criterios de evaluación son más similares. Por el contrario, las producciones intermedias (comprendidas entre los 
extremos) son las que presentan más dificultades y mayor disconformidad al ser evaluadas.

Por la dispersión de puntuaciones a través de las series se observa que los evaluadores han adquirido mayor firmeza en sus convicciones respecto a la calidad de las producciones.

En la serie 2 ya se ha comentado la incidencia del efecto "ecuación personal» de los evaluadores, interesa ahora subrayar la repercusión de este efecto en la evaluación de la serie 3. Efectivamente, la confrontación de las dispersiones de la serie I y 3 para los mismos niveles de escritura muestra que es en la última serie donde los evaluadores discrepan más.

Comparando las dos series de la misma composición - I y 3 - se aprecia que hay una tendencia a reducir la distancia entre los valores minimo y máximo de las medias en la serie 3 (ver cuadro II). Interesa señalar que otro de los efectos generados por la inclusión de la serie 2 en posición intermedia puede ser la reducción de amplitud entre los valores medios de la serie 3. Nuevas investigaciones deberán confirmar con mayor precisión estos hechos.

Cuadro II

\begin{tabular}{|c|c|c|c|c|c|c|c|}
\hline \multirow{2}{*}{$\begin{array}{l}\text { Niveles de construcción } \\
\text { de escrituras espontáneas }\end{array}$} & \multicolumn{7}{|c|}{ Valores medios de las escrituras } \\
\hline & \multicolumn{2}{|c|}{ Serie I } & \multicolumn{2}{|c|}{ Serie 2} & \multicolumn{2}{|c|}{ Serie 3} & $\overline{\mathbf{X}}$ total \\
\hline No diferenciadas. & & $\begin{array}{l}0,79 \\
0,66\end{array}$ & & 0,50 & & $\begin{array}{l}0,75 \\
0,75\end{array}$ & 0,89 \\
\hline $\begin{array}{l}\text { Diferenciadas por cantidad, repertorio y posi- } \\
\text { ción } \ldots \ldots \ldots \ldots \ldots \ldots \ldots \ldots \ldots \ldots \ldots \ldots \ldots \ldots\end{array}$ & $\begin{array}{l}\mathrm{K} \\
\mathrm{O}\end{array}$ & $\begin{array}{l}1,66 \\
1,08\end{array}$ & $\begin{array}{l}\mathrm{a} \\
\mathrm{h}\end{array}$ & $\begin{array}{l}0,91 \\
1,66\end{array}$ & $\begin{array}{l}15 \\
21\end{array}$ & $\begin{array}{l}1,66 \\
1,66\end{array}$ & 1,43 \\
\hline $\begin{array}{l}\text { Diferenciadas con valor sonoro convencional . } \\
\text { Silábicas }\end{array}$ & $\mathrm{H}$ & 1,25 & $\begin{array}{l}d \\
i\end{array}$ & $\begin{array}{l}1,58 \\
1,75\end{array}$ & 9 & 1,25 & 1,45 \\
\hline Sin valor sonoro convencional . . . . . . & $\begin{array}{l}N \\
S\end{array}$ & $\begin{array}{l}1,36 \\
1,08\end{array}$ & $\underset{\mathrm{j}}{\mathrm{j}}$ & $\begin{array}{l}0,83 \\
1,41\end{array}$ & $\begin{array}{l}10 \\
18\end{array}$ & $\begin{array}{l}1,50 \\
1,25\end{array}$ & 1,23 \\
\hline Con valor sonoro convencional $\ldots \ldots \ldots$ & $\begin{array}{l}\text { G } \\
\text { I }\end{array}$ & $\begin{array}{l}0,91 \\
1,83\end{array}$ & & & $\begin{array}{r}4 \\
\mathrm{I} 2\end{array}$ & $\begin{array}{l}1,66 \\
2,12\end{array}$ & 1,63 \\
\hline $\begin{array}{l}\text { Silábico-alfabéticas con valor sonoro conven- } \\
\text { cional } \ldots \ldots \ldots \ldots \ldots \ldots \ldots \ldots \ldots \ldots \ldots \ldots\end{array}$ & $\begin{array}{l}\mathrm{D} \\
\mathrm{P}\end{array}$ & $\begin{array}{l}3,25 \\
2,41\end{array}$ & & & $\begin{array}{r}1 \\
20\end{array}$ & $\begin{array}{l}2,58 \\
2,25\end{array}$ & 2,62 \\
\hline Alfabéticas con valor sonoro convencional & $\begin{array}{l}\mathbf{L} \\
\mathbf{R}\end{array}$ & $\begin{array}{l}4,71 \\
4,88\end{array}$ & & & $\begin{array}{r}3 \\
14\end{array}$ & $\begin{array}{l}4,66 \\
3,70\end{array}$ & 4,48 \\
\hline
\end{tabular}

Las escrituras diferenciadas, diferenciadas con valor sonoro convencional y silábicas sin valor sonoro convencional, no obtienen puntuaciones medias que muestren con evidencia la adquisición de nuevos conocimientos por parte del niño. Los valores de dichas medias son próximos y no progresivos. La comparación de las medias de las escrituras de estos niveles señala que es en la serie 2 donde ha habido más discrepancias por parte de los evaluadores. Las medias para cada una de las copias en esta serie, respecto a las de las series 1 y 3 , son a la vez más bajas y más altas.

Aplicando incluso el procedimiento de multicorrección en vistas a atenuar la excesiva severidad o indulgencia de los jueces, resulta que sólo los alumnos muy próximos al dominio de las características convencionales del sistema escrito - correspondencia sonora y valor sonoro convencional - lograría superar satisfactoriamente esta evaluación. La media total de las tres series se establece en $\bar{X}=1,70$, lo que supone que el 67,64 por 100 de producciones de los alumnos obtendrían un suspenso. Pero una producción correspondiente a un nivel conceptual alto, como ya se ha dicho, no garantiza el aprobado. Esto demuestra que los jueces consideran también otros parámetros ajenos a la calidad de la construcción. A continuación, se comentarán las justificaciones que han utilizado los jueces al evaluar. 
II. Proceso de atribución

de los puntajes

\section{II.a) Verbalizaciones}

Mediante el análisis de las verbalizaciones de los evaluadores emitidas en el transcurso del acto de evaluar, se puede acceder a las informaciones que ellos han seleccionado en las copias. Estas verbalizaciones son de muy distinta índole. Se han agrupado en dos grandes bloques: verbalizaciones justificativas y peticiones de información.

1. Verbalizaciones justificativas: se ha considerado verbalización justificativa toda producción verbal enunciada durante el proceso de evaluación, que no fuera solicitud de información. Se recordará que junto a la puntuación en la escala cerocinco puntos se pedía a los evaluadores justificación del puntaje otorgado. El objetivo de esta justificación era doble: por un lado, ver qué aspectos de la escritura infantil se constituyen en observables para los maestros con experiencias en estas edades, y, por otro, gracias a esta explicitación, conocer los criterios usados para puntuar. El recuento de las verbalizaciones justificativas se ha hecho por «informaciones temáticas mínimas». Es decir, cada justificación se ha subdividido según los enunciados que aportan informaciones de las copias de distinta significación ${ }^{3}$.

Las verbalizaciones justificativas se han agrupado en dos: uno, con las verbalizaciones referidas a las copias, y el otro, con las referidas a la tarea de evaluar.

Después del análisis de las verbalizaciones justificativas y a modo de resumen se puede señalar (cf. cuadro III):

Verbalizaciones justificativas referidas a las escrituras: después de la «lectura» de las producciones escritas, los evaluadores producen enunciados descriptivos referidos a datos directamente observables, o bien juicios sugeridos por las producciones. Esto caracteriza la siguiente tipología de verbalizaciones: características de los resultados escritos, juicios sobre el acto de escribir realizado por los niños, juicios sobre el nivel de los niños mediante su "performance» en las producciones escritas, juicios sobre el nivel de los niños vinculado a otros factores y juicios sobre los niños.
- Características de los resultados escritos: los evaluadores han observado en las producciones infantiles los siguientes aspectos:

- Aspectos formales de la escritura (linearidad, direccionalidad, compaginación, tipo de letra...).

- Presencia de dibujo acompañando a la producción escrita.

- Convencionalidad de las letras (orientación y forma).

- Repertorio, posición y cantidad de las letras.

- Influencia del nombre propio como patrón de base para la construcción de escrituras y como proveedor de repertorio.

- Presencia de un modelo propio para la palabra común a dos producciones ("gato» $y$ "el gato bebe leche»).

- Menor o mayor proximidad de la producción al modelo correcto: presencia de correspondencia sonora y de valor sonoro convencional.

- Atribución correcta o incorrecta del valor sonoro convencional.

- Separación de palabras.

- Cambios en los procedimientos de escritura de un mismo sujeto.

- Finalmente, observaciones sobre el tipo de copias que componen las series.

Los evaluadores han demostrado gran capacidad para seleccionar informaciones de las muestras de escritura. A pesar de ello, estas informaciones no les han permitido establecer criterios de evaluación estables. La posibilidad de observar y la de interpretar los datos observados aparecen, de este modo, como dos actividades independientes.

- Juicios sobre el acto de escribir realizado por los niños:

Las escrituras han sugerido a los evaluadores la atribución de intencionalidad en la consecución de unas metas determinadas en los actos gráficos de los niños. Esta intencionalidad es juzgada en función de los resultados gráficos realizados.

- Juicios sobre los niños y juicios 


\section{VERBALIZACIONES JUSTIFICATIVAS REFERIDAS A LAS ESCRITURAS}

- Características de los resultados escritos:

- Lineralidad: «escribe recto»

- Compaginación: «escribe una debajo de la otra»

- Cambio en el tipo de letra: «hay distinto tipo de

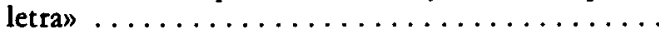

- Presencia de dibujo: «hay dibujo y grafías» ....

- Convencionalidad (forma y orientación): «hay letras mal orientadas», "hay palos de más» .....

- Posición: «hay letras repetidas en distinto lugar"

- Cantidad (cf. palabras/oración): "pone más letras

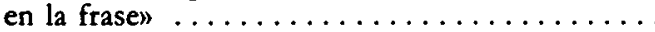

- Procedencia del repertorio: "hay letras de su nombre»"

- Modelo propio (cf. «gato» en palabra y oración)

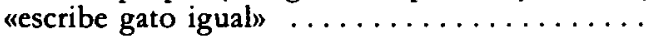

- Valor sonoro convencional: ausencia: "no tiene relación»

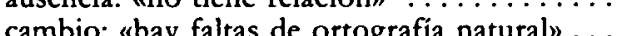
presencia: "hay letras de las palabras dictadas"

- Correspondencia sonora silábica: «faltan letras».

- Separación de palabras en oración: «separa bien"

- Cambio de procedimiento: «a veces escribe letras sueltas y otras no se entiende"

- Confrontación de la calidad de las series: «las de esta serie son peores»

- Juicios sobre el acto de escribir:

- Presencia de letras no convencionales: «no sabe escribirlas», «intenta poner símbolos», "no intenta

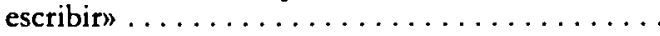

- Presencia de letras convencionales: «intenta escribir», «intenta poner letras»................

- Diferenciación en el resultado gráfico: «intenta poner la letra...», «intenta diferenciar palabras»

- Proximidad con el modelo convencional: uescribe mejor", «escribe bastante»

- Juicios sobre los niños:

- Presencia de dibujo acompañando las escrituras: "entiende lo que se le ha dicho" ...........

- Errores en la atribución de VSC: "pronuncia mal»

- Compaginación: «es ordenado», «es desordenado»

- Autocorrecciones: "es inseguro» ..........

- Presencia de rotaciones: "es zurdo»..........

- Cambio de procedimiento en la construcción de las escrituras: «está cansado»

- Juicios sobre el nivel de los niños mediante su "performance" en las escrituras:

- Presencia de letras no convencionales: «tiene problemas de orientación espacial», «tiene problemas de dominio del lápiz»

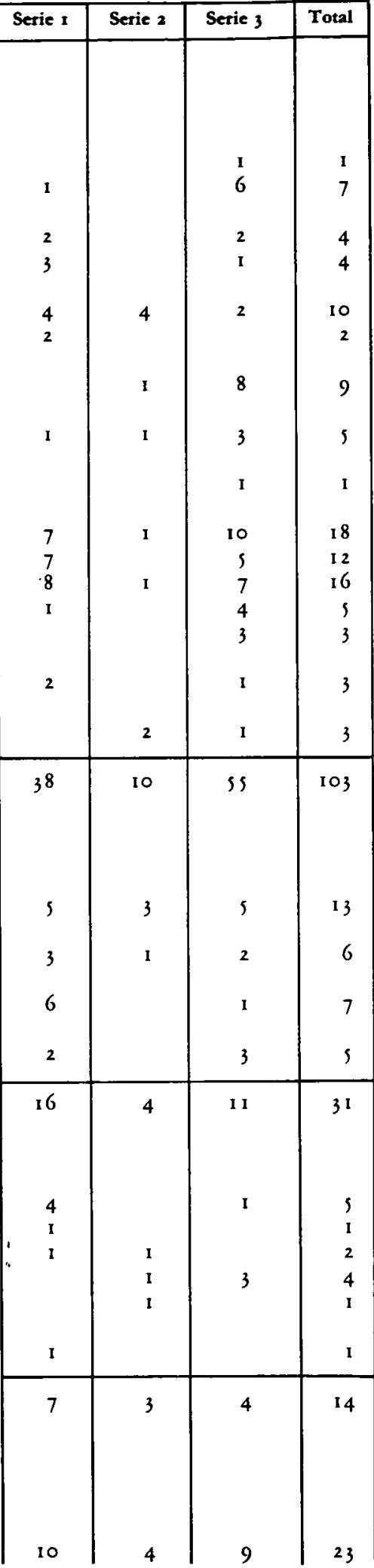


- Procedencia repertorio usado: "pone las que ve», "pone las que le suenan", «las que le han enseñado"

- Ausencia de vocales: "no sabe ni las vocales" .

- Presencia de vocales: «sabe las vocales» .......

- Ausencia de consonantes: uno sabe las consonantes" .......................

- Presencia de consonantes: «sabe alguna conso-

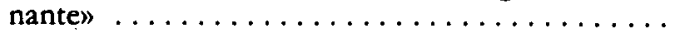

- Calidad gráfica de la producción: «falta preparación", "tiene buena preparación"

- Juicios sobre el nivel de los niños vinculado a otros factores:

- Jerarquización de las letras: «sólo pone las letras fáciles, las vocales" ..................

- Tamaño de las formas gráficas: "para la edad que tiene escribe muy pequeño" . . . . . . . . . . .

- Procedimiento de realización: «escribe al azar» .

- Jerarquización de las lenguas: «para ser en catalán

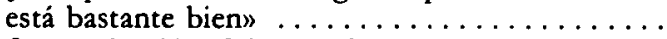

- Jerarquización del tipo de letra usado: «tendría que escribir en cursiva y no mayúscula" .......

- Calidad producción (relación edad o nivel escolar)

- Presencia de modelos escolares diferidos: «no sabe poner gato pero sí pipan.

\section{VERBALIZACIONES JUSTIFICATIVAS}

REFERIDAS A LA TAREA DE EVALUAR PROPUESTA

- Anticipación del procedimiento que seguirán para evaluar: «empezaré por éstos» ..............

- Desarrollo del acto de evaluar:

- Dificultades: «esto es muy difícil» ...........

- Requisitos profesionales: "tendriamos que

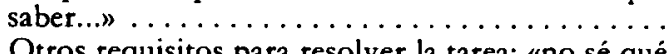

- Otros requisitos para resolver la tarea: «no sé qué

criterios usary .......
- Atribución de puntaje:

- Indefinido: «pondría más

- Confrontación de puntajes: «ésta y ésta .......

- Adaptación de la escala: "pongo medio punto»

- Confrontación edad-puntaje: «es pequeño» .....

- Confrontación puntaje-nivel escolar: «es parvularion.

- Confrontación puntaje-edad-nivelescolar: «es repetidons

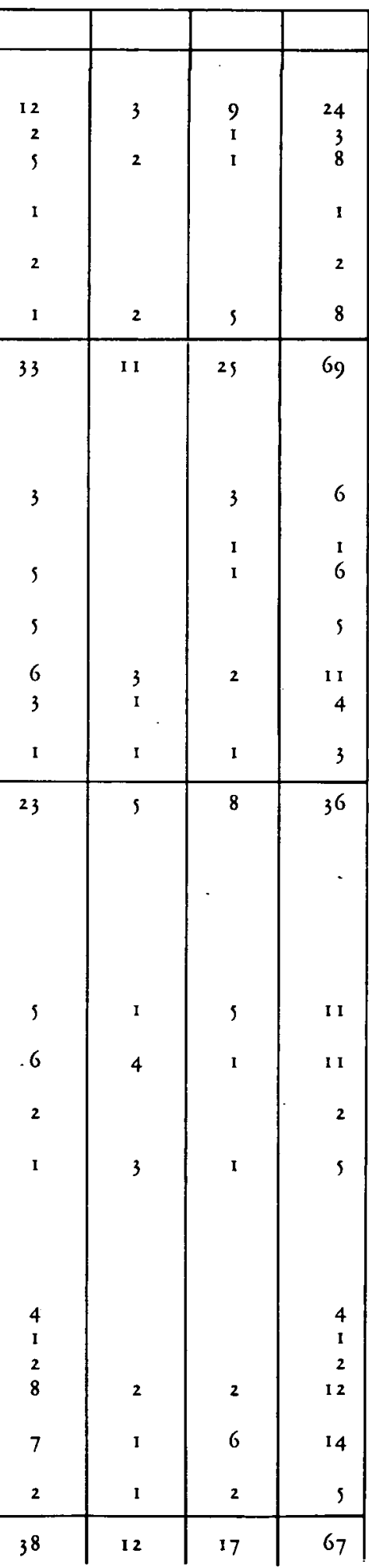

* Entre comillas se han transcrito verbalizaciones textuales de los evaluadores que ilustran los indices definidos. 


\begin{tabular}{|c|c|c|c|c|}
\hline Verbalizaciones justificativas & Serie $I$ & Serie 2 & Serie 3 & Total \\
\hline $\begin{array}{l}\text { VERBALIZACIONES JUSTIFICATIVAS } \\
\text { REFERIDAS A LAS ESCRITURAS }\end{array}$ & & & & \\
\hline $\begin{array}{l}\text { Características de los resultados escritos (observables) } \\
\text { Juicios sobre el acto de escribir, sobre los niños, sobre } \\
\text { el nivel de los niños mediante su "performance", } \\
\text { sobre el nivel de los niños vinculados a otros factores }\end{array}$ & 38 & I0 & is & 103 \\
\hline $\begin{array}{l}\text { Verbalizaciones justificadas referidas a la tarea de eva- } \\
\text { luar } \ldots \ldots \ldots \ldots \ldots \ldots \ldots \ldots \ldots \ldots \ldots \ldots \ldots \ldots\end{array}$ & 38 & 12 & 17 & 67 \\
\hline
\end{tabular}

sobre el nivel de los niños a través del resultado de la escritura.

Estos dos tipos de juicios remiten a características generales (inseguridad, desorden, etc.) o competencias específicas, tópicas, que en las últimas décadas se han relacionado con el aprendizaje de la lengua escrita (dominio del trazo, del espacio, etc.). Determinadas prácticas pedagógicas de sustrato psicológico asociacionista sostienen que el aprendizaje de la lengua escrita debe iniciarse a posteriori del «dominio de unos hábitos conductuales-sociales" y de la adquisición de una serie de actividades previas o "prerrequisitos» ligados al manejo del instrumento y del espacio gráfico. Desde esta perspectiva, ciertas características del sujeto (por ejemplo, zurdera) o de sus producciones (por ejemplo, el tipo de repertorio usado) pueden interferir en el logro de los objetivos pedagógicos fijados desde la enseñanza. Los enunciados incluidos en estos dos apartados desvelan que las conceptualizaciones de los evaluadores son próximas a las explicaciones perceptivomotrices de la adquisición del lenguaje escrito.

- Juicios sobre el nivel de los alumnos, vinculados a otros factores:

Los juicios reunidos bajo este título informan de las conceptualizaciones que los evaluadores tienen acerca del propio objeto de conocimiento o, más precisamente, de cómo la lengua escrita es significada desde la enseñanza. Basta como ejemplo señalar que para los evaluadores, las letras pueden ser «fáciles o difíciles», que hay tipos de letra "más propias de la enseñanza que otras" (cursiva, por ejemplo), etc.

También los evaluadores han manifestado ciertas expectativas sobre lo que a determinada edad o nivel escolar deben hacer los niños: «inicialmente la letra grande», «letra cursiva», etc.

Por último, destacar que el total de frecuencia de aparición de enunciados generados por la observación de las escrituras o por juicios respecto a las mismas, se invierte en el transcurso del acto de evaluación. Contrastando las series i y 3 , ambas de 13 copias, se observa mayor número de juicios en la serie $\mathrm{I}$ y descenso en la 3 , mientras que sucede lo contrario en cuanto a los observables. Ello indica que la posibilidad de extraer información a través de un acto de «lectura» de las producciones, es una actividad que los evaluadores aprenden mediante la mayor familiarización con las escrituras infantiles. Es factible interpretar que la mayor facilidad para obtener datos directamente de las escrituras hace disminuir la recurrencia a juicios ${ }^{4}$.

Verbalizaciones justificativas sobre la tarea de evaluar: en primer lugar, los sujetos entrevistados anticipan espontáneamente el orden que seguirán para evaluar las copias de una misma serie. Este orden es iniciar la evaluación según la edad de los niños, las características de convencionalidad de las copias, el tipo de letra, etc., entre otros.

En segundo lugar, frecuentemente, los evaluadores se refieren a la dificultad de la tarea de evaluar. En efecto, la tarea propuesta supone establecer operaciones a dos niveles: de clasificación y de seriación. Dadas las producciones de forma simultánea los sujetos deben encontrar indices que permitan establecer criterios excluyentes y agrupar las escrituras de acuerdo con estos criterios. Posteriormente, los rangos resultantes deben ser seriados.

El tercer aspecto hace referencia a las 
relaciones que los evaluadores establecen entre los puntajes, o más específicamente la anticipación justificativa del puntaje y la edad, nivel escolar de los alumnos o ambos a la vez. De estos comentarios se deduce que el nivel de adquisición del sistema escrito por parte de los alumnos está directamente vinculado a estos factores. Los evaluadores señalan de este modo la dependencia entre la adquisición y la enseñanza escolar. Como sabemos, en muchas escuelas los objetivos de enseñanza del sistema escrito correspondiente al primer trimestre del último grado de parvulario - época en que se recogieron las escrituras- son enseñar las vocales y alguna consonante «fácil». El hecho de que los alumnos utilicen estas letras al construir las escrituras es acogido por parte de los observadores como índice de la adquisición lograda. La producción del alumno debe mostrar todo aquello que el maestro "ha enseñado» en el aula. Esto permite desvelar otra conceptualización subyacente a la evaluación, ligada a un punto de vista asociacionista: la situación de aprendizaje es, para los evaluadores, especular a la de enseñanza.

También las verbalizaciones referidas a la tarea de evaluar disminuyen en el transcurso de la evaluación (cf. series 1 y 3 ).

En resumen, respecto a las verbalizaciones justificativas puede afirmarse que, en tanto las informaciones intrínsecas a las producciones no son observables ni relevantes para los evaluadores, éstos recurren a informaciones extrínsecas para justificar la evaluación. La incorporación de informaciones extrínsecas a las escrituras en el transcurso de la evaluación permite evidenciar dos hechos. Por un lado, perfilar las dificultades generadas $e$ implicitas al desarrollo de este acto pedagógico particular. Por otro lado, acceder a algunas de las conceptualizaciones de la escritura en tanto objeto de conocimiento y objeto de enseñanza y aprendizaje manejadas por los evaluadores en el transcurso de esta situación.

2. Peticiones de información: los evaluadores no se han ceñido a las condiciones de la situación experimental en lo que respecta a la solicitud de información. Se - recordará que esta posibilidad se les ofrecía para la evaluación de la tercera serie. Sin embargo, los sujetos han pedido in- formación en todas las series. Además de las peticiones directas, de forma interrogativa, los evaluadores han expresado la necesidad de poder disponer de más datos. Para los evaluadores la "carencia» de datos, propia de la situación experimental, es una dificultad para lograr más precisión en la evaluación. Una vez más, el énfasis es colocado en los datos que son irrelevantes para lograr entender los procesos que guían la adquisición de los alumnos. A nuestro modo de ver, es la posibilidad de tener una teoria interpretativa de las producciones lo que puede orientar la práctica pedagógica, entre ellas la práctica de evaluar, y no disponer de datos sobre el sistema de enseñanza del maestro.

En el cuadro IV están clasificadas las preguntas - directas e indirectasformuladas por los sujetos al experimentador.

La frecuencia de las solicitudes formuladas disminuye en la tercera serie. El tipo de preguntas más frecuentes se refieren a la tarea de evaluar en sí misma (¿la copia $\mathrm{X}$ ya la he puntuado?, ¿cuántos puntos he puesto a la copia $\mathrm{X}$ ?) y a la confirmación de datos ya facilitados inicialmente (tanto de la situación diagnóstica como de los sujetos que han realizado las copias). Resalta la insistencia de los sujetos en recurrir a informaciones ya dadas y la dificultad para preguntar sobre parámetros de las escrituras no incluidos en la producción misma. En efecto, ninguno de los evaluadores ha preguntado sobre aspectos tales como el proceso de construcción de las escrituras, la confirmación por parte del niño en la atribución de valor sonoro convencional, la interpretación de la producción hecha a posteriori por el niño, etc. Estas son, para nosotros, informaciones esenciales que deben confirmarse en el momento del diagnóstico. La presencia de valor sonoro convencional o de correspondencia sonora en las escrituras pueden ser atribuidas a la intencionalidad y no al azar a posteriori de dicha confirmación. Pero es evidente que estas informaciones tienen cabida en un marco teórico de interpretación que no es el de los evaluadores. Ellos han ceñido sus preguntas a la confirmación de datos relevantes desde el marco teórico que sostiene su práctica. 


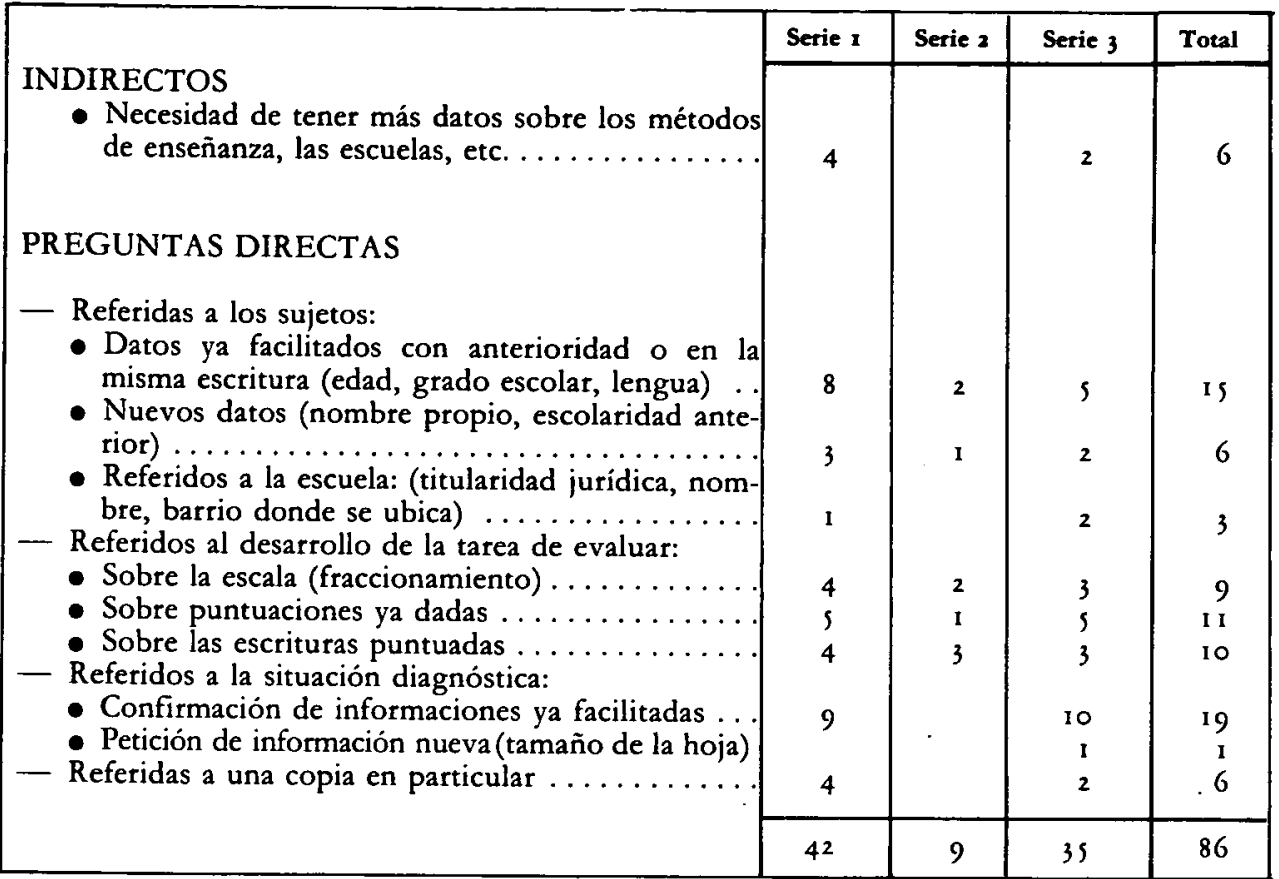

\section{II.b. Procedimientos de atribucion}

Analizadas las puntuaciones otorgadas por los evaluadores a las producciones que componen las tres series y las verbalizaciones justificativas, interesa averiguar cuál ha sido el proceso seguido para adjudicarlas. En el acto de evaluar confluyen comportamientos de dos tipos. Uno que consiste en seleccionar la información contenida en las copias a partir de una serie de índices y otro que se efectúa al comparar las copias con un modelo de referencia. La constitución del modelo de referencia del evaluador se efectúa por la puesta a punto de un conjunto de correspondencias entre ciertos productos esperados y ciertos ajustes en la escala de notación. Los productos esperados resultan de la selección entre los productos posibles de la tarea. Esta selección se realiza, por un lado, según las informaciones a priori - generales y particulares de los alumnos productores-, y, por otro lado, por las informaciones secuenciales generadas en el momento de evaluar. En el presente trabajo las informaciones secuenciales no se consideran dado que las copias de cada serie fueron presentadas simultáneamente.
Por último, en el modelo de referencia también confluye el "producto-norma» que los evaluadores establecen según el cuerpo de conocimientos y los objetivos pedagógicos que tengan de la tarea. El modelo de referencia resulta, de este modo, constituido por los productos esperados, el producto norma y los ajustes de la escala: lo esencial de la evaluación es el resultado de la actividad de un comparador que confronta, por un lado, un modelo de referencia, y del otro, una producción real (cf. Noizet y Caverni, 1978).

Esta investigación trata de desvelar cuáles son los aspectos de las escrituras tempranas relevantes para los evaluadores. Hemos visto que las copias, además de corresponder a producciones de distinto nivel conceptual, contenian informaciones de distinto rango (calidad de trazo, presencia o no de dibujo, distinto tipo de letra, linearidad, direccionalidad, etc.). Es probable que estas informaciones hayan incidido en la evaluación que han realizado los jueces. Es importante, por tanto, presentar cuál ha sido el manejo que de estas informaciones han hecho los jueces. El tipo de criterios utilizados y el uso de estos criterios serán los puntos a tratar a 
continuación, dado que ambos aspectos pueden aclarar tanto la divergencia constatada entre los evaluadores como el modo en que han resuelto la tarea de evaluar cada uno de ellos.

\section{Tipos de criterios de evaluación de las escrituras}

En las verbalizaciones justificativas del apartado anterior se han presentado muestras de los índices usados por los jueces para valorar las escrituras. Hemos agrupado los indices de acuerdo a dos tipos de criterios 5: uno, relacionado con el lenguaje escrito y su proceso de adquisición, y otro, relacionado con otros factores.

Los criterios relativos al lenguaje escrito $\mathrm{y}$ su proceso de adquisición están relacionados con los parámetros relevantes desde la teoría psicogenética de la conceptualización de la escritura. Ellos son: linealidad, cantidad, posición y repertorio de las grafías; posibilidad de establecer una correspondencia sonora entre unidades del lenguaje y unidades gráficas y la atribución de valor sonoro convencional a dichas unidades, entre otros.

Los índices considerados por los evaluadores, vinculables a los criterios relacionados con el lenguaje escrito y su proceso de adquisición son los siguientes:

- Linealidad de las escrituras.

- Direccionalidad.

- Repertorio:

- Inventario de las grafias.

- Variedad: presencia de vocales únicamente o de vocales y consonantes.

- Tipo de unidades usadas y convencionalidad de las grafias (forma y orientación).

- Posición de las letras.

- Longitud de las escrituras continuas (no discretas) o cantidad de letras en las escrituras discretas.

- Relación entre cantidad de letras y segmentación del enunciado (correspondencia sonora).

- Patrón propio (cf. escritura de «gato" como palabra y en la oración).

- Atribución de valor sonoro convencional.

- Ortografia.
Separación de palabras en la oración.

- Procedimiento usado en la construcción.

Los criterios relacionados con otros factores son aquellos cuya relación con las propiedades que definen el sistema escrito y su adquisición, no está suficientemente explicitada.

Los indices considerados, relacionados con criterios dependientes de otros factores son:

- Aspectos formales de las producciones ${ }^{6}$.

- Compaginación.

- Tamaño de las letras.

- Pulcritud.

- Habilidad en el manejo del instrumento.

- Lengua en que se ha realizado la producción.

- Nivel escolar de los alumnos.

- Edad: variación en meses.

- Presencia de modelos escolares.

- Presencia de dibujos acompañando la escritura.

- Tipo de letra usado en las escrituras.

Por último, respecto a los criterios de evaluación usados, cabe señalar que los jueces también han utilizado juicios. Los criterios mencionados hasta el momento surgen a partir de los índices constituidos en la recogida de información observable en las copias. Los juicios son acerca del acto de escribir, sobre los niños y acerca de cómo es conceptualizada la lengua escrita y la "performance» de los niños por los evaluadores. Para nosotros es difícil inferir si ha habido y cuáles han sido los indices que los jueces han manejado para conformar dichos juicios. Por ejemplo, una pseudoletra del tipo $\exists$ en una escritura ha dado lugar, en distintos evaluadores, a verbalizaciones del tipo: «tiene una letra mal orientada», "el niño que lo ha escrito es zurdo" o "este niño aún está inmaduro». Mientras que la primera afirmación se remite a la convencionalidad de las letras, tanto la segunda como la tercera remiten a juicios sobre características del niño.

\section{Uso de los criterios}

Los evaluadores han usado dos procedimientos distintos para justificar las producciones. Uno, consistente en enumerar 
caracteristicas de las producciones sin confrontarlas con el modelo convencional. Otro, en el que la producción se confrónta con el modelo a través de un acto de recogida de información mínima. En ambos casos puede o no emitirse además juicios sugeridos por las producciones.

La recogida de información mínima se ha aplicado para describir las escrituras más cercanas a las convencionales. Es decir, en estas escrituras, preferentemente, han recogido indices negativos que tienen estatus de «error» -error como distancia al modelo correcto-. Observables del tipo de separación de palabras, correcta atribución del valor sonoro convencional o juicios dificiles de interpretar, del tipo «escribe mejor», "escribe bastante", son usados para calificar las escrituras silábico-alfabéticas y alfabéticas. La atribución de puntaje en estos casos, ha sido en base a la sustracción de puntos del límite máximo de la escala. Por otro lado, conviene también señalar que estas escrituras más cercanas a las convencionales son las primeras que los evaluadores han puntuado en la serie uno y tres en las que en el momento de justificar se ha priorizado los criterios relacionados con el lenguaje escrito y su adquisición. En consecuencia, han obtenido puntajes más altos y acordes con el nivel de construcción.

Por el contrario, en las escrituras menos evolucionadas y en las intermedias, el procedimiento usado para justificar los puntajes ha sido el de enunciar características muy generales, pero no generalizables. Estas son afirmaciones del tipo: «no tiene relación con las palabras dictadas», aplicadas a escrituras con correspondencia sonora silábica y/o valor sonoro convencional. En estos casos, los evaluadores no han logrado encontrar en las producciones la puesta en correspondencia y/o la atribución de valor usadas por los niños. Han sido formuladas en positivo o en negativo. Por ejemplo, el valor sonoro convencional ha actuado como indicador bien positivo, bien negativo, en contraste, la correspondencia sonora de tipo silábico ha sido usada como indicador negativo. Todas las escrituras silábicas han sido comentadas en negativo: «le faltan letras".

Los juicios elaborados por los evalua- dores a partir de contrastar las producciones con sus conceptualizaciones particulares sobre la enseñanza de la lengua escrita, también han originado índices negativos y positivos. Entre los primeros, cabe contar la aparición de letras de origen extraescolar; es decir, no consideradas del repertorio inicial de enseñanza o las producciones realizadas con letra de imprenta, tipo de letra que normalmente no es enseñada en la escuela. Entre los positivos, por el contrario, están las producciones realizadas con letra cursiva, con letras del repertorio inicial o incluso modelos iniciales provinientes de la enseñanza del tipo pipa, papá a pesar de ser escrituras-copia (modelo diferido) y no producciones construidas. Otros ejemplos son: el mayor puntaje otorgado a la producción indiferenciada con dibujo, frente a las indiferenciadas sin dibujo y la subvaloración de las escrituras silábicas con valor sonoro convencional exclusivamente sobre vocales, frente las mixtas (sobre vocales y consonantes). Para estos casos las justificaciones son «aunque no hay letras, comprende lo que le han dictado y se entiende», por la presencia del dibujo y «este niño pone consonantes y son más difíciles que las vocales». Sabemos que, a pesar de la enorme diferencia que separa el dibujo del sistema escrito, en los programas establecidos por la Administración $\mathrm{y}$ en la práctica escolar, a menudo, el inicio de la enseñanza de la escritura está asociado con la representación icónica porque se considera que «ambas formas de representación tienen por objetivo la comunicación». Asimismo, en la práctica escolar, suelen jerarquizarse las letras según una supuesta escala de dificultad establecida a partir de la articulación fonética, la frecuencia de aparición de las letras en las palabras o la menor o mayor dificultad grafomotriz de las formas de las letras.

Las escrituras más primitivas y las intermedias, justificadas a partir de la enunciación de características del tipo comentado, son las que resultan más dificiles de evaluar $y$, en consecuencia, obtienen mayor dispersión (cf. análisis de los puntajes otorgados para la serie 2). En efecto, el hecho de no juzgar todas las producciones o al menos las que para los evaluadores tienen alguna característica semejante, con los mismos índices, origina que cada producción que se evalúa sea considerada como muestra particular a l'a 
que, en consecuencia, debe evaluarse con criterios particulares ${ }^{7}$. Incluso cuando los evaluadores han clasificado copias supuestamente semejantes, ha predominado la contaminación y la particularización de criterios, de forma que han terminado justificando cada una de las producciones de modo distinto e incluso otorgando distinto puntaje. La evaluación de las escrituras primitivas y las intermedias da como resultado que obtengan distinta puntuación pares de escrituras de un mismo nivel conceptual y a la inversa, pares de distinto nivel conceptual, el mismo puntaje.

La atribución de puntajes a las escrituras menos evolucionadas e intermedias ha sido adjudicada por sumación de puntos a partir del límite inferior de la escala. Estos hechos confirman la hipótesis de que la frecuencia de aparición de los elementos «negativos» en relación con los "positivos", tienen consecuencias sobre la naturaleza de los indices recogidos y modifica el sentido de utilización de la escala (Noizet y Caverni, 1978).

\section{CONSIDERACIONES FINALES}

La evaluación es el componente del proceso de enseñanza-aprendizaje quizá más importante, porque tiene efectos tanto para el sistema escolar como para los individuos. Los resultados de la evaluación de uno de los aprendizajes iniciales, la adquisición de la lengua escrita, producen muchos fracasos iniciales ${ }^{8}$ que, a lo largo de la EGB, pueden incrementarse. Las distintas modalidades de evaluación en general (Allal, 1980) y de evaluación de la lengua escrita en particular, se corresponden con distintas conceptualizaciones de la práctica pedagógica. No se trata, por tanto, de lograr evaluaciones más exactas, entendiendo como tales las que dan menos margen de error estadistico o de promover una evaluación «continua" consistente en multiplicar datos parciales, sino de plantearse cómo y para qué se evalúan.

En el presente trabajo se han constatado hechos que demuestran las dificultades que conlleva evaluar escrituras iniciales incluso para maestros avezados en la tarea de enseñar a leer y a escribir. Nos propusimos como condiciones de estudio entrevistar sólo a maestros con experien- cia en preescolar y ciclo inicial, neutralizar el factor conocimiento personal del alumno para evitar interferencias de otros datos que no fueran las propias escrituras y dar toda la información que los jueces demandaran a fin de facilitar la tarea. Sin embargo, la tarea resultó compleja para cada uno de los evaluadores, por las características de las escrituras seleccionadas. Muchas de ellas en el ámbito escolar son desechadas por ser consideradas no escritura.

Los hechos constatados no hacen más que revelar tal dificultad: dispersión entre jueces, uso de indicadores irrelevantes, juicios elaborados en base a expectativas apriorísticas, referencia a un modelo convencional final, especialmente en el aspecto del valor sonoro convencional, y poca estabilidad en los criterios usados, entre otros. El producto norma se ha identificado con la escritura alfabética correcta. En consecuencia, a pesar de pertenecer las escrituras a alumnos de cinco años, mayoritariamente son suspendidas, mostrando la contradicción entre lo que los evaluadores dicen («a los cinco años los niños no tienen que saber escribir») y lo que realmente hacen en el transcurso de la evaluación. Esta contradicción, si bien puede ser atribuida a la naturaleza normativa de la lengua escrita, también evidencia que los evaluadores dificilmente admiten otras formas de escritura. El acercamiento progresivo al modelo alfabético, que supone la construcción de las escrituras, queda oculto en muchos casos para los jueces. Los hechos constatados muestran, por otro lado, que la aplicación de la multicorrección no es suficiente para lograr una evaluación más objetiva.

La complejidad de la tarea podria ser explicada por la falta de planificación en el desarrollo de la evaluación realizada. A nuestro entender, evaluar las escrituras infantiles exigía de los jueces una clasificación y una ordenación de las categorias establecidas en función de ella. Los jueces aportan datos ajenos a las producciones y los yuxtaponen a los observados. De este modo amplían el número de discriminadores, aspecto necesario para conseguir una evaluación más fiel. Pero una vez establecidos los discriminadores, la resolución de la tarea exige establecer una organización entre ellos, basada en un marco de interpretación adecuado que la haga posible. 
Hemos comprobado que los maestros han sido capaces de extraer muchas informaciones de las producciones observadas. Sin embargo, ¿por qué estas informaciones no han facilitado la planificación de la tarea de evaluar? Desde nuestro punto de vista, la teoria pedagógica de los maestros acerca de la lengua escrita (coincidente con las de mayor difusión en la actualidad), no da cuenta de los procesos de aprendizaje implicados. Las dificultades para interpretar los datos observados en las escrituras pueden relacionarse con la poca viabilidad para planificar la evaluación en base a las líneas evolutivas del proceso de construcción.

Es dificil pensar en una evaluación que no incluya la evolución de los procesos de aprendizaje. La aportación de las investigaciones sobre psicogénesis de la lengua escrita a la práctica escolar debe entenderse desde esta perspectiva; como proveedores de elementos que ayuden a entender al sujeto cognoscente en proceso de apropiación del sistema escrito.

\section{Notas}

1 Los niveles conceptuales de apropiación del sistema escrito reseñados en este trabajo, no suponen la adquisición progresiva lineal por parte de los niños. En investigaciones anteriores se han constatado distintos ritmos y patrones evolutivos (cf. Ferreiro y Gómez Palacios, 1982, fascículo 2).

2 En recientes investigaciones realizadas en Barcelona (Bellés et al, 1984, y Teberosky y Bellés en preparación) con niños urbanos, no hemos encontrado muestras de escrituras silábico-alfabéticas sin valor sonoro convencional ni alfabéticas sin valor sonoro convencional. Todos los niños entrevistados, capaces de establecer correspondencia sonora silábico-alfabética o alfabética, son también capaces de atribuir valor sonoro convencional. Sin embargo Ferreiro y Gómez Palacios recogieron escrituras de estas caracteristicas.

3 Por ejemplo el evaluador $\mathrm{S}_{4}$ dice de la escritura $\mathrm{G}$ : «este niño no tiene dominio del lápiz ni vagamente, / es un cúmulo de letras, / tiene intención de hacer todo el rato la «a», / a los cinco años tendria que saber escribir letras y éste no lo tiene nada claro, / pero como que tiene intención, pues o,s puntosm. Para analizar esta justificación, se ha dividido en cinco enunciados temáticos que han sido clasificados, respectivamente, en juicios sobre el nivel de los niños mediante su «performance» (problemas de dominio del lápiz), características de las escrituras (posición: cúmulo de letras), juicios sobre el acto de escribir (diferenciación en el resultado gráfico: intenta poner la letra...), juicios sobre el nivel vinculado a otros factores (calidad producción: edad) y juicios sobre el acto de escribir (presencia de letras convencionales: tiene intención).

4 También ha habido comentarios sobre la afectación que las escrituras han producido en los jueces, tales como "son divertidas", "qué gracia», "me gustan», etc. Estos comentarios han sido atribuidos a un conjunto de escrituras y no a una en particular.

5 Ningún evaluador ha explicitado sus criterios de evaluación. Los criterios, por tanto, han sido establecidos a partir de los índices expresados por las verbalizaciones. Ello ha supuesto una tarea de ordenación del material verbalizado en dos sentidos. Por un lado, reformulando los enunciados a nuestros parámetros. Por ejemplo, las observaciones respecto a «cambio en la calidad gráfica» remiten a modificaciones en los procedimientos de construcción de las escrituras usados por los niños. Por otro lado, analizando las distintas formulaciones bajo las que se ha denominado un mismo parámetro. Por ejemplo, "cúmulo de letras" y ulas mismas letras siempre repetidas aquí y allá» remiten a la posición como factor de diferenciación de las escrituras.

6 Estos aspectos formales, evidentemente, tienen que ver con el lenguaje escrito. En efecto, distintos tipos de texto escrito requieren determinadas compaginaciones, formas de titulación, etc. No obstante, en la tarea que los jueces deben evaluar, estos aspectos son irrelevantes.

7 Por ejemplo, el mismo evaluador, al evaluar las escrituras $\mathrm{S}$ y $\mathrm{N}$ de la serie I dice, respectivamente, «está hecha al azar, parece que no hay relación de las letras que pone y las palabras y además la letra no es caligráfica sino imprenta, pone las letras que ve por la calle. ¿Es posible que se llame Noelia? (pregunta dirigida al entrevistador), porque tiene letras de su nombre «a, i, ele» todo el rato; I punto» y «esta niña, Laura, ha escrito las letras de su nombre que le suenan, no tiene relación la palabra con la escritura, domina el trazo de estas letras y nada más, pero es pequeñita tiene , 1 años; ponle un In. En ambos casos se han yuxtapuesto criterios de adquisición con criterios dependientes de otros factores. Las dos escrituras pertenecen a un mismo nivel conceptual y han sido justificadas de manera distinta; en un caso es relevante la edad; en el otro, el tipo de letra. A pesar de ello, estos dos ejemplos obtienen puntajes iguales.

8 A pesar de la parcialidad de los datos reseñados en «Los resultados de la evaluación de las enseñanzas mínimas del ciclo inicial, claramente insatisfactorios», estudio realizado por la Inspección General de Educación Básica del Estado (Magisterio Español, 27-IV-1984), se da cuenta de que entre el 6s por 100 y el 35 por 100 de alumnos de ciclo inicial superan actividades de escritura (porcentaje dependiente de la actividad exigida: "técnica escribana» y «composición escrita», respectivamente. Si bien los indicadores utilizados no parecen ser los más adecuados, no por ello deja de ser preocupante la noticia.

\section{Resumen}

Este estudio analiza la evaluación en relación con una tarea escolar especifica, confrontando la adjudicación y justificación de la valoración obtenida en situación experimental con los niveles establecidos por investigaciones anteriores sobre la psicogénesis de adquisición de la lengua escrita. 
Se entrevistó a profesores de pre-escolar y ciclo inicial de EGB, solicitándose una evaluación de producciones escritas de distintos niveles conceptuales, producidas por alumnos de último preescolar (cinco-seis años). En el trabajo se analizan diez entrevistas.

Los resultados muestran que la tarea de evaluar escrituras tempranas presenta grandes dificultades. Como prueba están la dispersión de puntajes y falta de estabilidad de criterios usados, bechos que pueden ser atribuidos más a la inadecuación del marco teórico interpretativo usado por los evaluadores, que a dificultades imputables a las técnicas $e$ instrumentos de evaluación.

Se apunta la necesidad de aportar a la práctica pedagógica elementos que contemplen y permitan entender los procesos constructivos implicados en las escrituras para evaluar.

\section{Summary}

This paper analyses evaluation related to an specific scbool task. Provides a confrontation between evaluations results, obtained in experimental situation, specially their adjudication and interpretation, with former investigations in the field of the psychogenesis of the acquisition of written language.

Prescbool teacbers were interviewed and asked to evaluate diferent conceptual written levels, coming from pupulis of the last preschool year ( $5-6$ years old). This paper analyses 10 interviews.

Obtained data show that to evaluate early writing presents a lot of difficulties. The evidence is the wide range of scores and the lack of stability of the criteria used. This may be imputed more to unsuitable theoretic sets used, than to the evaluation technics.

Evidence is provided to demonstrate the need of introduce elements to the pedagogical practice, in order to understand the construction processes involved in the writing to be evaluated.

\section{Résumé}

Dans ce travail, on analyse l'evaluation par rapport à une tâcbe scbolaire specifique. Les résultats obtenus, son adjudication et son estimation, dans une situation d'experimentation sont confrontés avec d'autres, provenants des recherches antérieures, à propos du sujet de la psychogenése de facquisition de la langue écrite.

Mattres de préscolaire furent demandés d'évaluer productions écrites, de plurisieurs niveaux conceptuels, provenant des élèves du dernier année préscolaire ( $\mathrm{s}-6$ ans). Dans ce travail on analyse 10 régistres. Les résultats montrent que la tâcbe devaluer les prémières productions écrites a des grands difficultés. Les preuves son lampleur de la dispersion des points obtenus et la manque d"stabilité des répères employés. On peut établir que tout cela est en dépendance de Pinadéquation des cadres théoriques, et secondairement aux techniques employés.

On établit aussi le besoin d'introduire élements de la pratique pédagogique, pour comprendre les procés de constrution sous-jacents aux écrits à évaluer.

\section{Referencias}

Al.I.AI., L.: «Strategies d'évaluation formative: conception psycho-pédagogiques et modalités d'application». En L. Ail.ai., J. Cardinet y PH. PerRen()ud (eds.): L'evaluation formative dans un enseignement différencié. Berne: PETER LANG, 1979, 130-156: "Estrategias de evaluación formativa: concepciones psicopedagógicas $y$ modalidades de aplicación, en Infancia y Aprendizaje, 1980, $I I, 4-22$.

BELLLES, R., et al.: "La construcción de la lengua escrita: entre la copia y la construcción (comunicación)». I Congreso del Colegio Oficial de Psicólogos, volumen 2, Madrid, 1984.

Bonbolr, A.: "La docimologie", PUF, Paris, 1972. La docimologia, Ed. Morata, Madrid, 1974.

DE KETELE, J. M.: «Evaluación orientada a la intervención pedagógica», en A. BONBOIR: Una pedagogia para mañana, Madrid, Morata, 1975.

FERREIRO, E.: La psicogénesis de la lengua escrita y su relación con la evaluación pedagógica, resumen de la ponencia presentada a las Segundas Jornadas Nacionales de Psicologia Escolar, Caracas, mayo 1983 . No publicado.

Ferreiro, E.,, Gómez PAlacios, M., y col.: Análisis de las perturbaciones en el aprendizaje de la lecto-escritura, fascículos 1 y 2, Dirección General de Educación Especial, SEP-OEA, México, 1982.

Ferreiro, E., y Teberosky, A.: Los sistemas de escritura en el desarrollo del niño, México, Siglo XXI, 1979.

Forns, M.: "La evaluación del aprendizaje», en CoI.l. y Forns, M. (eds.), Areas de intervención de la psicologia, volumen I, Barcelona, Horsori, 1980.

Noizet, G., y Caverni, J. P.: Psychologie de Pévaluation scolaire, Paris, PUF, 1978.

PERrenoud, PH.: «De las diferencias culturales a las desigualdades escolares: la evaluación y la norma en una enseñanza indiferenciada", en L. Allal, J. CARDINet y PH. PERRENOUD (eds.), L'évaluation formative dans un enseignement differencie. Berne: Peter Lang, 1979, 20-59. Traducción: Infancia y Aprendizaje, 1981, núm. 14, 19-50. 